\title{
Synthesis and Optical Enhancement of Amorphous Carbon Nanotubes/Silver Nanohybrids via Chemical Route at Low Temperature
}

\author{
Tan Kim Han, Leo Bey Fen, Ng Meng Nee, and Mohd Rafie Johan \\ Nanomaterials Engineering Research Group and Advanced Materials Research Group, Department of Mechanical Engineering, \\ University of Malaya, Lembah Pantai, 50603 Kuala Lumpur, Malaysia
}

Correspondence should be addressed to Tan Kim Han; kimhan8419@gmail.com

Received 6 February 2014; Revised 10 May 2014; Accepted 12 May 2014; Published 5 June 2014

Academic Editor: Bingqing Wei

Copyright (C) 2014 Tan Kim Han et al. This is an open access article distributed under the Creative Commons Attribution License, which permits unrestricted use, distribution, and reproduction in any medium, provided the original work is properly cited.

\begin{abstract}
We report the synthesis of amorphous carbon nanotubes/silver $(\alpha \mathrm{CNTs} / \mathrm{Ag})$ nanohybrids via simple chemical route without additional reactant and surfactant at low temperature. Field emission scanning microscope (FESEM) and transmission electron microscope (TEM) confirmed formation of CNTs. X-ray diffraction (XRD) pattern confirmed the amorphous phase of carbon and the formation of Ag nanoparticles crystalline phase. Raman spectra revealed the amorphous nature of $\alpha \mathrm{CNTs}$. UV-visible spectroscopy showed enhancement of optical properties of $\alpha \mathrm{CNTs} / \mathrm{Ag}$ nanohybrids.
\end{abstract}

\section{Introduction}

Since the discovery of crystalline carbon nanotubes (CNTs) by Iijima [1], they have attracted worldwide interest due to their exceptional properties such as high mechanical strength, high electrical conductivity, and high thermal conductivity. Therefore, CNTs play a great role in a tremendously diverse range of research and application. However, crystalline CNTs pose a challenge for being produced in a large quantity due to their very critical deposition conditions like high operating temperature, expensive cost, long synthesis period, complex processing steps, and others [2]. In that light, amorphous carbon nanotubes ( $\alpha \mathrm{CNTs}$ ) have become alternative to the crystalline CNTs due to their ease of production in large quantities [3]. $\alpha \mathrm{CNTs}$ have unique amorphous structures, which are different from crystalline CNTs due to the wall composed of carbon clusters with a short-distance order or long-distance disorder [4]. The properties of CNTs are affected by their amorphous structural arrangement. They can be synthesized by arc discharge [5], chemical vapor deposition (CVD) [6], laser ablation [7], and chemical route [8].

Nevertheless, the $\alpha \mathrm{CNTs}$ properties can be improved for various potential applications through hybridization of
CNTs with noble metal such as silver [9], gold [10], and platinum [11] or with semiconductors such as cadmium selenide quantum dots [2]. The unique structure of CNTs enables them to be considered as a template for metal nanoparticles to form nanohybrids. In order to deposit nanoparticles on the inert CNTs wall, functional groups such as carboxylic acid, carbonyl, and hydroxyl groups need to be introduced onto the surfaces of CNTs by additional chemical treatment under acidic conditions. The functional groups created will give rise to the preferred nucleation site for metal deposition and also enhance the solubility of the CNT [12, 13]. Nanohybrids possess the combination of advantageous physical, chemical, and optical properties from both CNTs and metal nanoparticles. They could reveal the unexpected quantum effects and alter the band gaps of CNTs [2,3]. CNTs/Ag nanohybrids received considerable attention due to the outstanding characteristic such as high catalyst activity [14], great optical properties [15], electrochemical sensor [16], and bactericidal properties in biomedical materials [17]. From the approaches reported, the CNTs/Ag nanohybrids can be produced by physical evaporation, solid state reaction, wet chemical reaction, and electroless deposition [18].

In this paper, we report a simple method for the synthesis of $\alpha \mathrm{CNTs}$ and for the first time Ag nanoparticles attached 


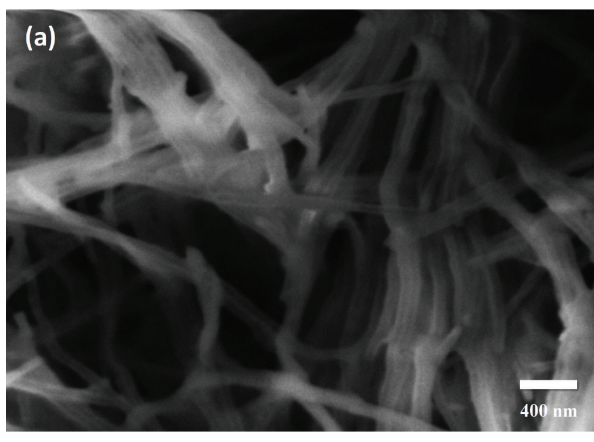

(a)

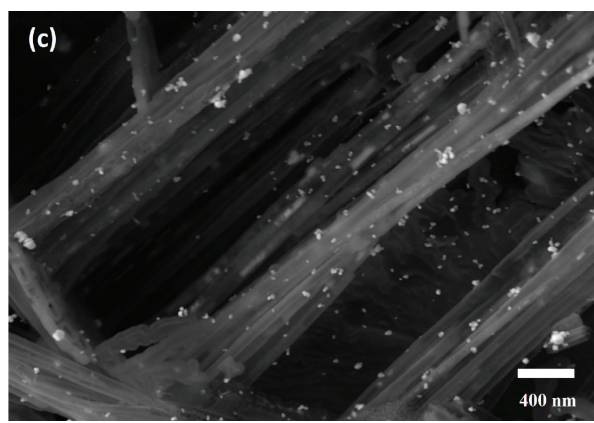

(c)

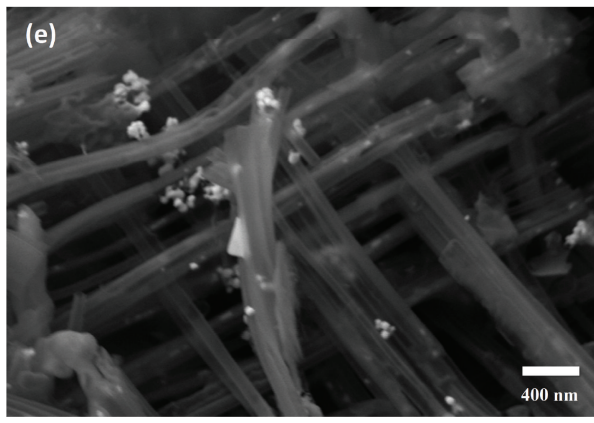

(e)

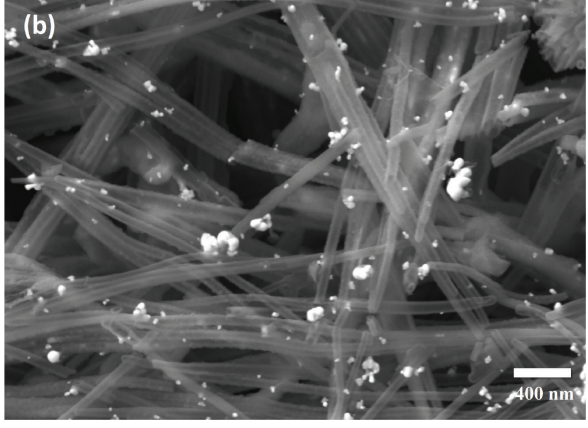

(b)

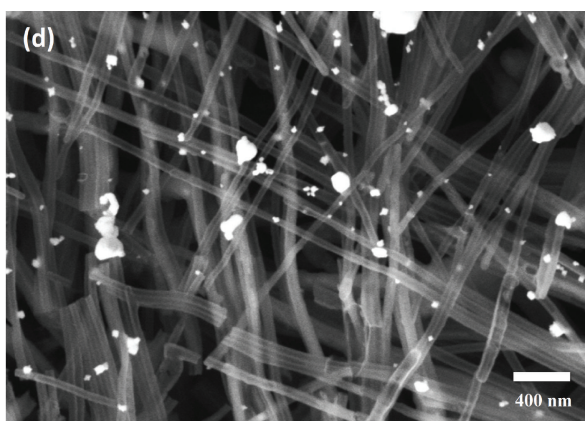

(d)

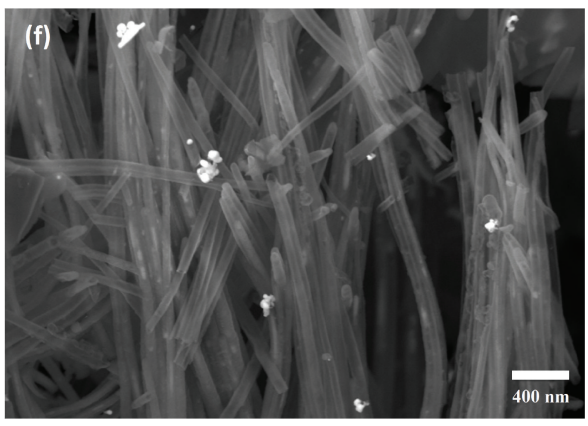

(f)

Figure 1: FESEM images of $\mathrm{HCl}$ functionalized $\alpha \mathrm{CNTH} / \mathrm{Ag}$ nanohybrids at different molars of $\mathrm{AgNO}_{3}$ : (a) $0 \mathrm{M}$, (b) $0.01 \mathrm{M}$, (c) $0.05 \mathrm{M}$, (d) $0.1 \mathrm{M}$, (e) $0.5 \mathrm{M}$, and (f) $1 \mathrm{M}$.

on the $\alpha \mathrm{CNTs}$ walls. The $\alpha \mathrm{CNT}$ s surface was first purified and functionalized by strong acids; carboxyl groups were added on nanotubes wall to create reaction point between Ag nanoparticles. The acid treated nanotubes act as a template and starting point for the formation of nanohybrids. The interactions between $\alpha \mathrm{CNTs}$ and Ag nanohybrids such as morphological, structural, elemental, and optical properties were investigated.

\section{Experimental}

2.1. Materials and Sample Preparation. Ferrocene, $\mathrm{Fe}\left(\mathrm{C}_{5} \mathrm{H}_{5}\right)_{2}$ $(98 \%)$, and ammonium chloride $\left(\mathrm{NH}_{4} \mathrm{Cl}\right)$ were purchased from Acros Organics and Fisher Scientific, respectively. Hydrochloric acid, $\mathrm{HCl}$ (37\%), was purchased from R\&M Chemicals and silver nitrate $\left(\mathrm{AgNO}_{3}\right)$ was purchased from Fisher Scientific. All chemicals were used without further purification. $\alpha \mathrm{CNTs}$ were prepared by mixing $2 \mathrm{~g}$ of $\mathrm{Fe}\left(\mathrm{C}_{5} \mathrm{H}_{5}\right)_{2}$ and $4 \mathrm{~g}$ of $\mathrm{NH}_{4} \mathrm{Cl}$ together in a covered crucible. The sample was heated in the furnace at $200^{\circ} \mathrm{C}$ for $30 \mathrm{~min}$ and allowed to cool at room temperature. The as-produced $\alpha \mathrm{CNT}$ s were washed consecutively with diluted $\mathrm{HCl}$ and deionized water for several times and dried at $40^{\circ} \mathrm{C}$ for $24 \mathrm{~h}$. The purified sample was functionalized by immersing in $\mathrm{HNO}_{3}$ at room temperature. The samples then were washed several times with deionized water and then dried at $40^{\circ} \mathrm{C}$ for $24 \mathrm{~h}$. The functionalized $\alpha \mathrm{CNT}$ s were hybridized with Ag nanoparticles.

$100 \mathrm{mg}$ of $\alpha \mathrm{CNTs}$ was soaked in $200 \mathrm{~mL}$ deionized water for $5 \mathrm{~min}$ under ultrasonic dispersion. Different concentrations of $\mathrm{AgNO}_{3}(0.01 \mathrm{M}, 0.05 \mathrm{M}, 0.1 \mathrm{M}, 0.5 \mathrm{M}$, and $1 \mathrm{M}$ ) were added into the $\alpha \mathrm{CNT}$ s aqueous solution and continuously stirred at room temperature for $20 \mathrm{~h}$. The product was filtered and washed with deionized water sequentially and dried at $40^{\circ} \mathrm{C}$ for $24 \mathrm{~h}$. The nanohybrids functionalized by $\mathrm{HCl}$ 


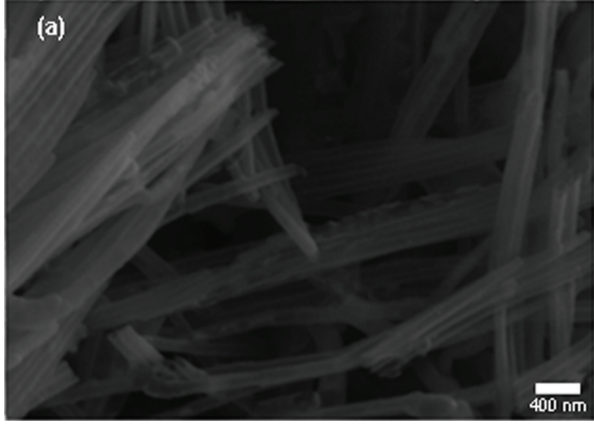

(a)

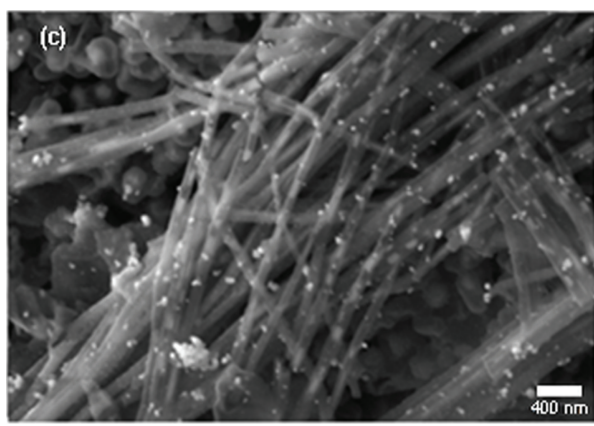

(c)

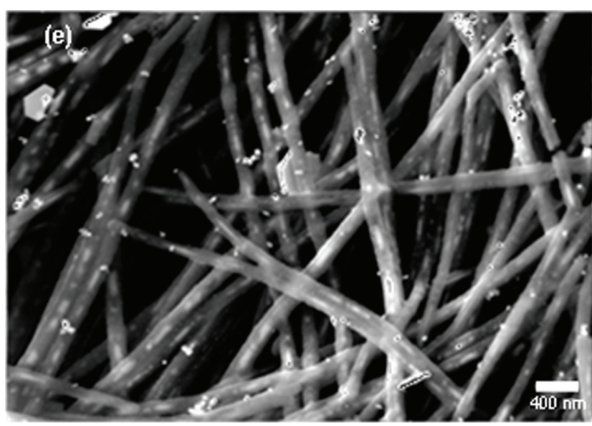

(e)

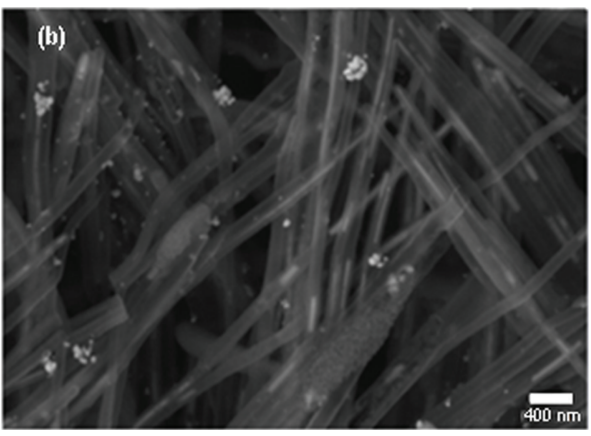

(b)

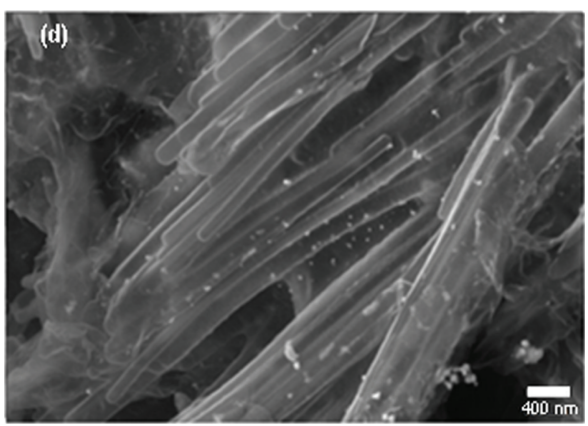

(d)

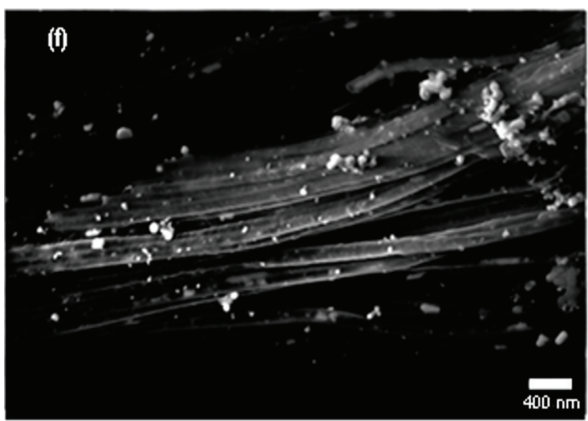

(f)

FIGURE 2: FESEM images of $\mathrm{HNO}_{3}$ functionalized $\alpha \mathrm{CNTN} / \mathrm{Ag}$ nanohybrids at different molars of $\mathrm{AgNO}_{3}$ : (a) $0 \mathrm{M}$, (b) $0.01 \mathrm{M}$, (c) $0.05 \mathrm{M}$, (d) $0.1 \mathrm{M},(\mathrm{e}) 0.5 \mathrm{M}$, and (f) $1 \mathrm{M}$.

and $\mathrm{HNO}_{3}$ were denoted as $\alpha \mathrm{CNTH} / \mathrm{Ag}$ and $\alpha \mathrm{CNTN} / \mathrm{Ag}$, respectively.

2.2. Characterizations. The morphological structures of all samples were observed using field emission scanning electron microscope (FESEM, AURIGA Zeiss) and transmission electron microscope (TEM, Philips CM12) operated at 10 and $200 \mathrm{kV}$, respectively. Structural characterization was performed using X-ray diffractometer (XRD, Siemen D500) with $\mathrm{Cu} \mathrm{K} \alpha$ radiation $(40 \mathrm{kV}, 40 \mathrm{~mA}$ ). The optical absorption spectra were recorded using UV/VIS spectrophotometry (Varian CARY 50 Series). Raman spectra for all samples were recorded using inVia Raman microscope (RENISHAW, United Kingdom).

\section{Results and Discussion}

The FESEM images of $\alpha \mathrm{CNTH} / \mathrm{Ag}$ and $\alpha \mathrm{CNTN} / \mathrm{Ag}$ nanohybrids at different molars of $\mathrm{AgNO}_{3}$ were shown in Figures 1 and 2, respectively. Figures $1(\mathrm{a})$ and 2 (a) present FESEM images of the $\mathrm{HCl}$ and $\mathrm{HNO}_{3}$ functionalized $\alpha \mathrm{CNTs}$ prior to hybridization. Both images show tubular structures and are present in a bundle form due to van der Waals forces. Meanwhile, Figures 1(b)-1(f) and 2(b)-2(f) show the FESEM images of hybridized $\mathrm{HCl}$ and $\mathrm{HNO}_{3}$ functionalized $\alpha \mathrm{CNTs}$ at different molars of $\mathrm{AgNO}_{3}$. The walls of $\alpha \mathrm{CNT}$ were randomly coated with $\mathrm{Ag}$ nanoparticles. The interaction sites of $\alpha \mathrm{CNT}$ and Ag nanoparticles vary with increasing molarity of $\mathrm{AgNO}_{3}$. It was found that $\mathrm{Ag}$ nanoparticles tend to aggregate at higher molar of $\mathrm{AgNO}_{3}$.

Figures 3 and 4 show the TEM images of $\mathrm{HCl}$ and $\mathrm{HNO}_{3}$ functionalized $\alpha \mathrm{CNTs} / \mathrm{Ag}$ at different molars of $\mathrm{AgNO}_{3}$. It is clearly observed that $\mathrm{Ag}$ nanoparticles are attached heterogeneously on the nanotubes wall. For $\mathrm{HCl}$ functionalized $\alpha \mathrm{CNTH} / \mathrm{Ag}, \mathrm{Ag}$ nanoparticles are highly concentrated at specific sites on the CNTs wall at higher molar of $\mathrm{AgNO}_{s}$. Meanwhile, for $\mathrm{HNO}_{3}$ functionalized $\alpha \mathrm{CNTN} / \mathrm{Ag}$, 


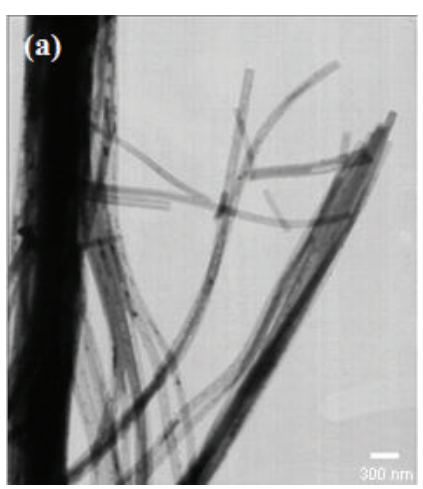

(a)

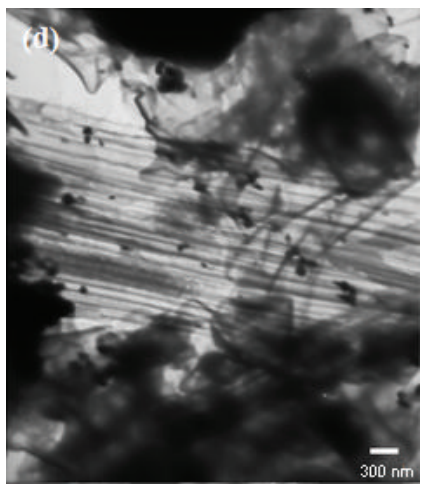

(d)

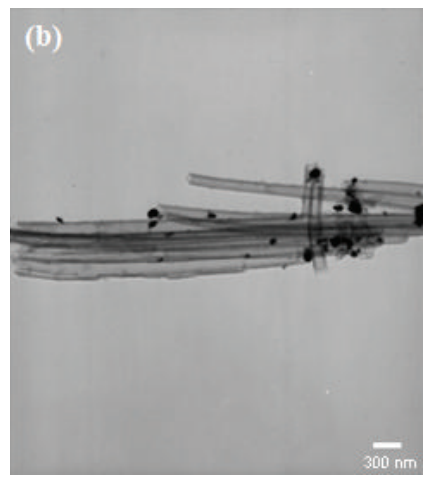

(b)

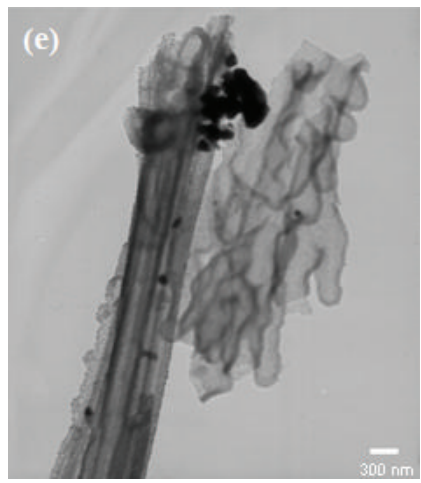

(e)

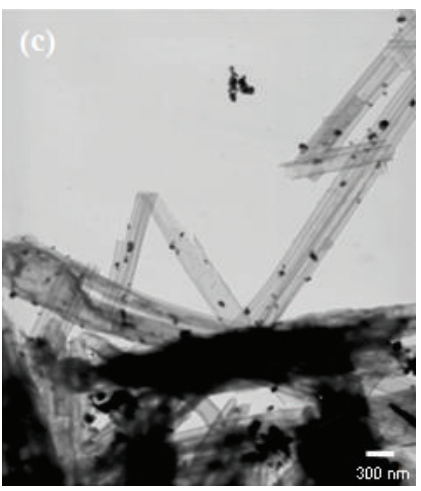

(c)

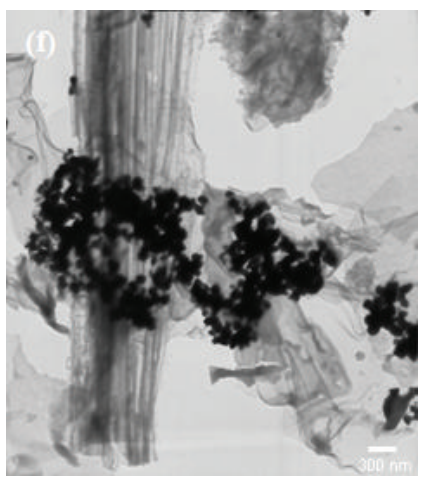

(f)

Figure 3: TEM images of $\mathrm{HCl}$ functionalized $\alpha \mathrm{CNTH} / \mathrm{Ag}$ nanohybrids at different molars of $\mathrm{AgNO}_{3}$ : (a) $0 \mathrm{M}$, (b) $0.01 \mathrm{M}$, (c) $0.05 \mathrm{M}$, (d) $0.1 \mathrm{M}$, (e) $0.5 \mathrm{M}$, and (f) $1 \mathrm{M}$.

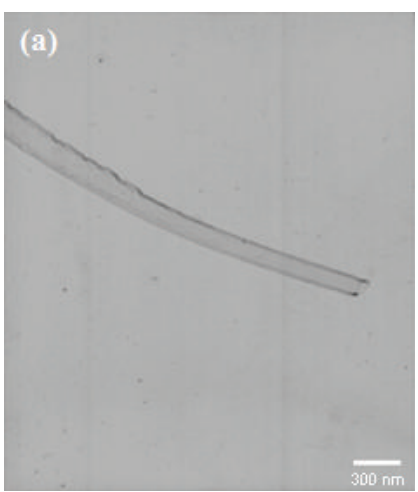

(a)

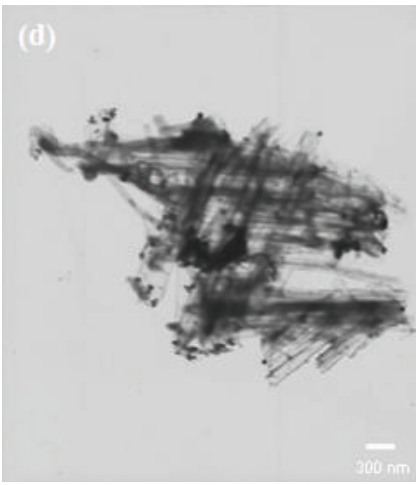

(d)

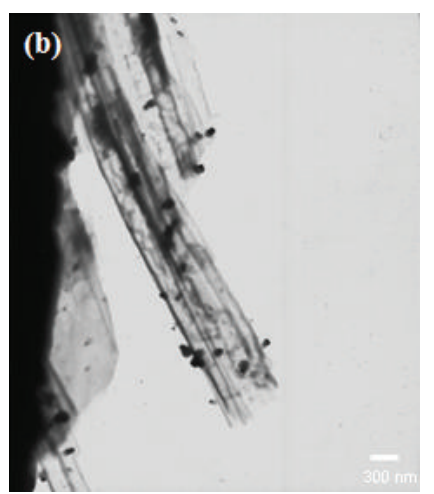

(b)

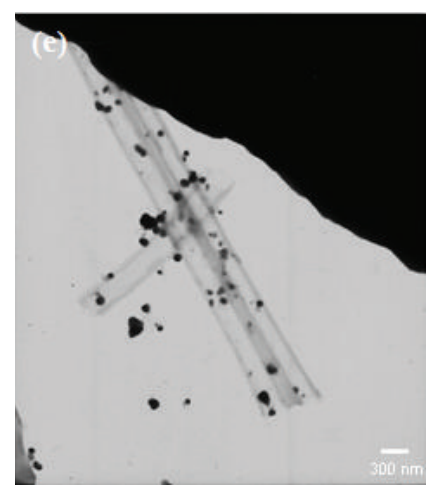

(e)

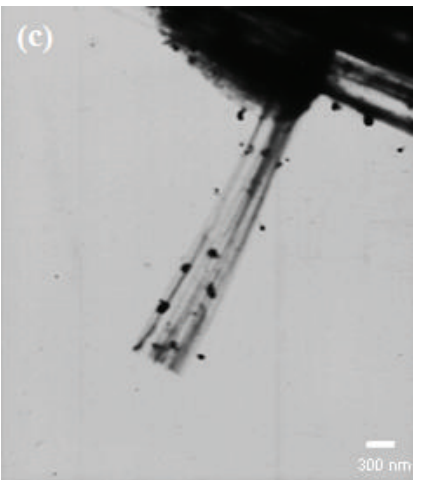

(c)

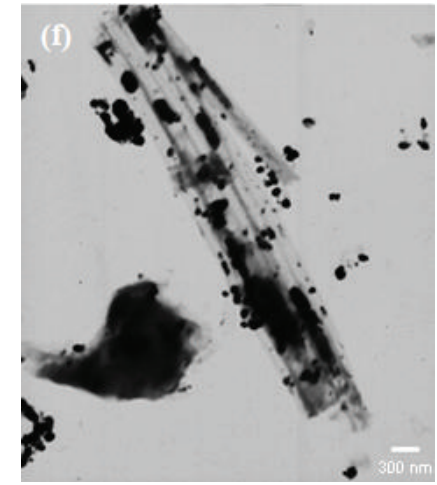

(f)

FIGURE 4: TEM images of $\mathrm{HNO}_{3}$ functionalized $\alpha \mathrm{CNTN} / \mathrm{Ag}$ nanohybrids at different molars of $\mathrm{AgNO}_{3}$ : (a) $0 \mathrm{M}$, (b) $0.01 \mathrm{M}$, (c) $0.05 \mathrm{M}$, (d) $0.1 \mathrm{M}$, (e) $0.5 \mathrm{M}$, and (f) $1 \mathrm{M}$. 


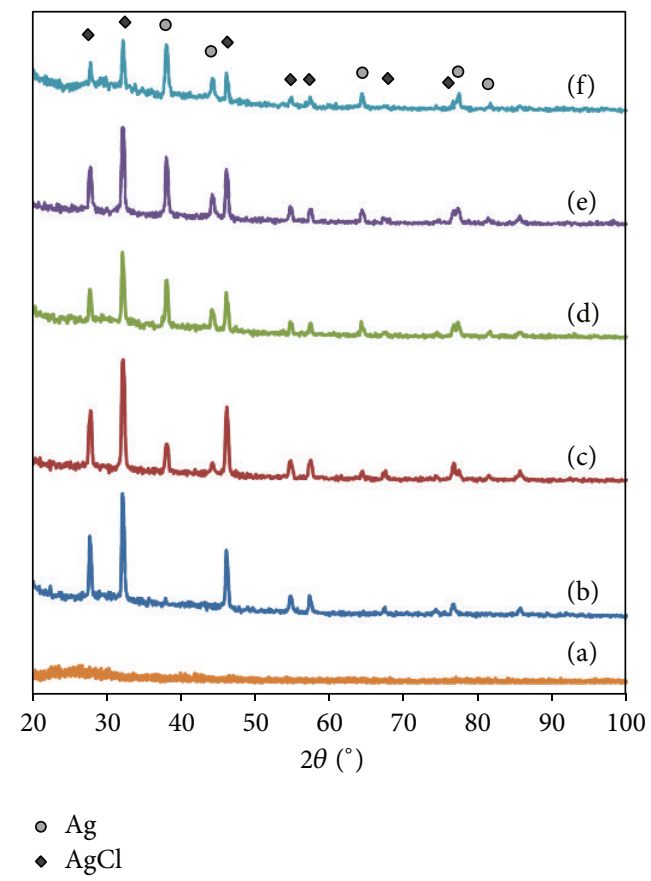

FIGURE 5: XRD patterns of $\mathrm{HCl}$ functionalized $\alpha \mathrm{CNTH} / \mathrm{Ag}$ nanohybrids at different molars of $\mathrm{AgNO}_{3}$ : (a) $0 \mathrm{M}$, (b) $0.01 \mathrm{M}$, (c) $0.05 \mathrm{M}$, (d) $0.1 \mathrm{M}$, (e) $0.5 \mathrm{M}$, and (f) $1 \mathrm{M}$.

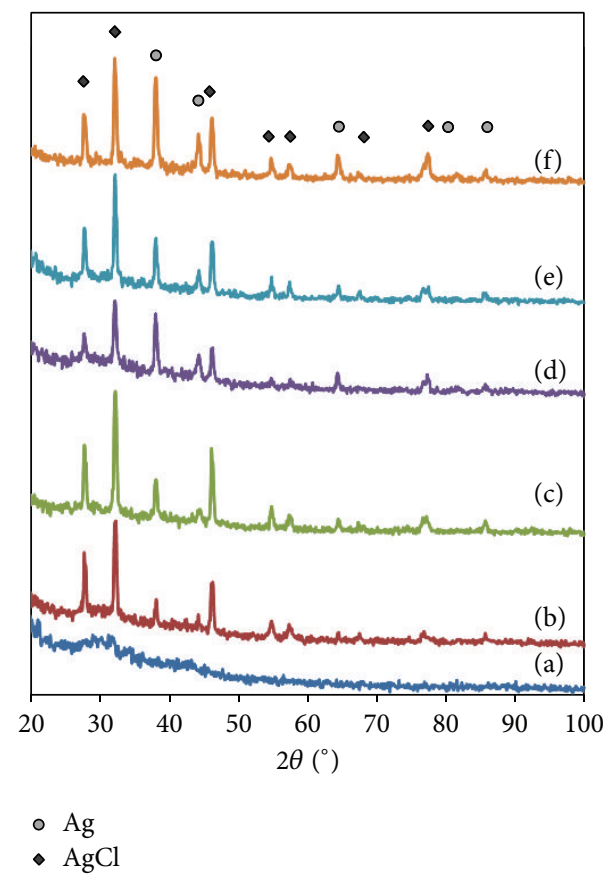

FIGURE 6: XRD pattern of $\mathrm{HNO}_{3}$ functionalized $\alpha \mathrm{CNTN} / \mathrm{Ag}$ nanohybrids at different molars of $\mathrm{AgNO}_{3}$ : (a) $0 \mathrm{M}$, (b) $0.01 \mathrm{M}$, (c) $0.05 \mathrm{M}$, (d) $0.1 \mathrm{M}$, (e) $0.5 \mathrm{M}$, and (f) $1 \mathrm{M}$.

Ag nanoparticles are more scattered on the CNTs wall and not influenced by the various molars of $\mathrm{AgNO}_{3}$. This evidence confirmed that $\mathrm{HNO}_{3}$ manages to create more the reaction side than $\mathrm{HCl}$.

The XRD patterns of all samples obtained are illustrated in Figures 5-6. The as-synthesized $\alpha \mathrm{CNTs}$ are amorphous

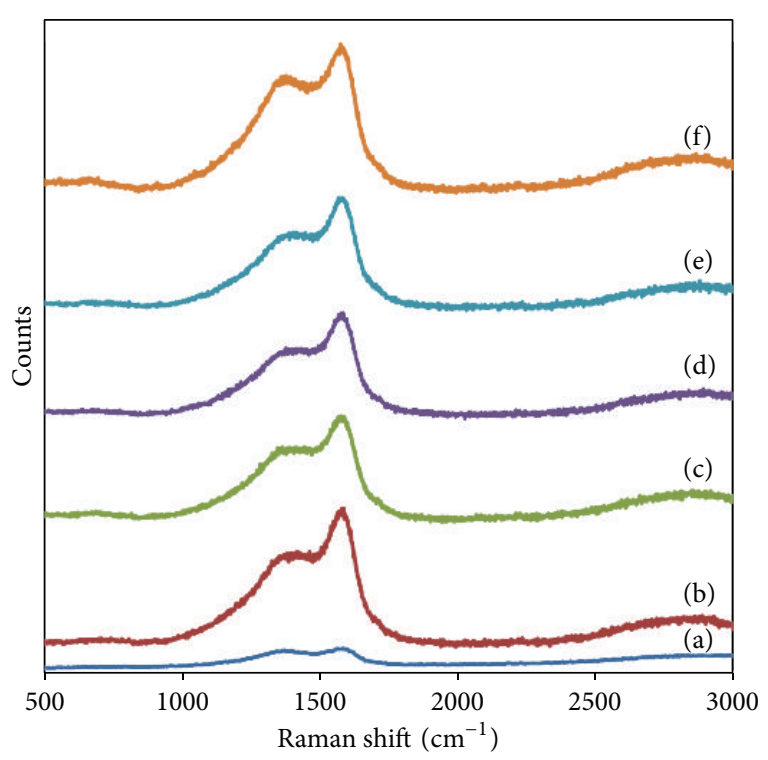

FIgURE 7: Raman spectra of $\mathrm{HCl}$ functionalized $\alpha \mathrm{CNTH} / \mathrm{Ag}$ nanohybrids at different molars of $\mathrm{AgNO}_{3}$ : (a) $0 \mathrm{M}$, (b) $0.01 \mathrm{M}$, (c) $0.05 \mathrm{M}$, (d) $0.1 \mathrm{M}$, (e) $0.5 \mathrm{M}$, and (f) $1 \mathrm{M}$.

with the broad peak at around $26^{\circ}$ corresponding to (002) Bragg's reflections plane of graphite. The XRD patterns of the hybridized samples show diffraction peaks at angles of $38^{\circ}$, $44^{\circ}, 64^{\circ}, 77^{\circ}$, and $82^{\circ}$ corresponding to (111), (200), (220), (311), and (222) planes of Ag nanoparticles structure. This result indicates that $\mathrm{Ag}$ nanoparticles are well crystallized on $\alpha \mathrm{CNTs}$ wall. Meanwhile, additional peaks at angles of $28^{\circ}, 32^{\circ}$, $46^{\circ}, 55^{\circ}, 58^{\circ}, 68^{\circ}$, and $77^{\circ}$ are also observed corresponding to the face-centered cubic (FCC) structure of AgCl. The formation of $\mathrm{AgCl}$ is resulted from the reaction of $\mathrm{Ag}^{+}$with $\mathrm{Cl}^{-}$during purification process [19]. However, $\mathrm{AgCl}$ peaks decrease significantly at higher molar of $\mathrm{AgNO}_{3}$. The trend is similar for $\mathrm{HNO}_{3}$ functionalized $\alpha \mathrm{CNTN} / \mathrm{Ag}$ nanohybrids.

Figures 7-8 show the Raman spectra of $\mathrm{HCl}$ and $\mathrm{HNO}_{3}$ functionalized $\alpha \mathrm{CNTs} / \mathrm{Ag}$ nanohybrids at different molars of $\mathrm{AgNO}_{3}$ which are characterized by D and $\mathrm{G}$ bands at 1380 and $1583 \mathrm{~cm}^{-1}$, respectively. The G-band is attributed to the vibration of $\mathrm{sp}^{2}$ bonded carbon atoms [20] and D band is corresponding to the disordered carbon [21,22]. The intensity of $\mathrm{G}\left(I_{\mathrm{G}}\right)$ band is increased significantly compared to $\mathrm{D}$ band $\left(I_{\mathrm{D}}\right)$ for all molars of $\mathrm{AgNO}_{3}$. The similar trend is observed in $\mathrm{HNO}_{3}$ functionalized $\alpha \mathrm{CNTN} / \mathrm{Ag}$ nanohybrids. The decrease of $I_{\mathrm{D}} / I_{\mathrm{G}}$ ratio indicated the increase of crystallinity in nanohybrids' samples. The D and G bands are enhanced significantly after the deposition of $\mathrm{Ag}$ nanoparticles on $\alpha$-CNTs. This can attribute to the plasmonic properties of Ag nanoparticles [23]. The depositions of $\mathrm{Ag}$ nanoparticles on $\alpha$-CNTs wall directly affected the disorder degree in nanotubes due to the presence of crystalline $\mathrm{Ag}$ nanoparticles. This will enhance the $\mathrm{G}$ band significantly. The results are consistent with the previous XRD patterns.

Figures 9-10 show the absorption spectra for all samples. The absorption peak at around $260 \mathrm{~nm}$ is corresponding to the $\alpha \mathrm{CNTs}$ [24]. It was found that the absorbance increases 


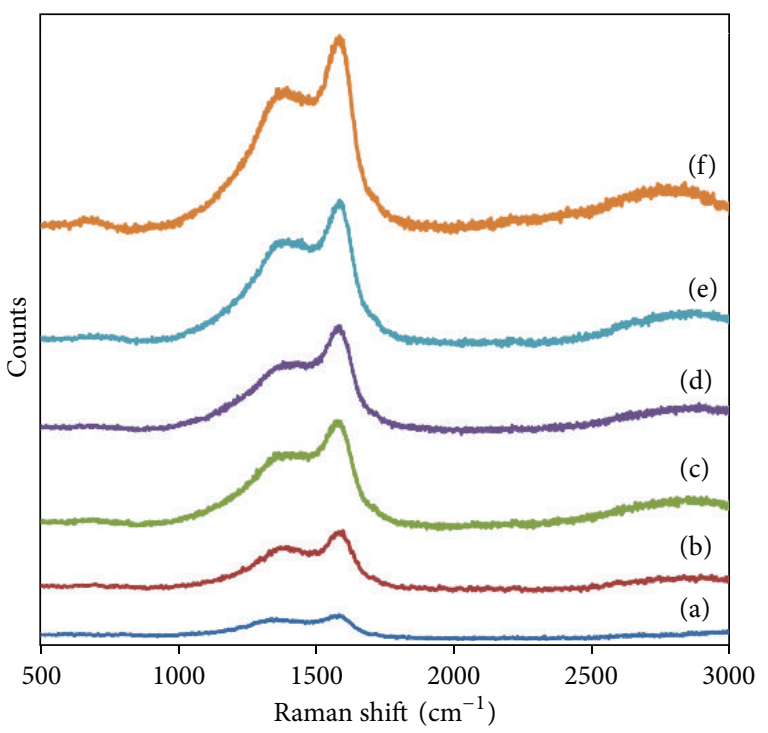

FIGURE 8: Raman spectra of $\mathrm{HNO}_{3}$ functionalized $\alpha \mathrm{CNTN} / \mathrm{Ag}$ nanohybrids at different molars of $\mathrm{AgNO}_{3}$ : (a) $0 \mathrm{M}$, (b) $0.01 \mathrm{M}$, (c) $0.05 \mathrm{M}$, (d) $0.1 \mathrm{M}$, (e) $0.5 \mathrm{M}$, and (f) $1 \mathrm{M}$.

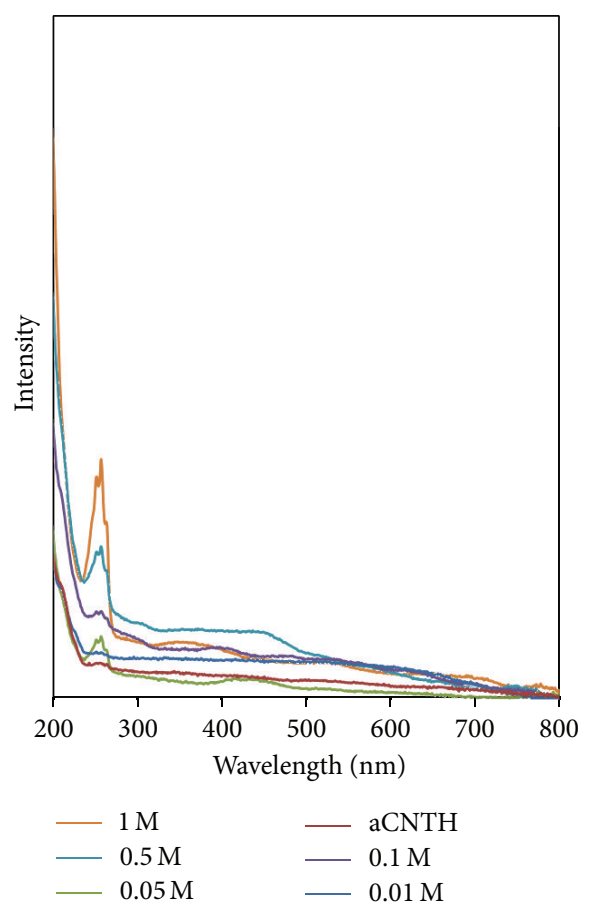

Figure 9: Absorption spectra of $\mathrm{HCl}$ functionalized $\alpha \mathrm{CNTH} / \mathrm{Ag}$ nanohybrids at different molars of $\mathrm{AgNO}_{3}$.

with the increase of molarity of $\mathrm{AgNO}_{3}$. The linear increase of absorbance indicates that the Ag nanoparticles are well bonded on nanotubes' walls [25]. In addition, there is another band observed in the visible region at $440 \mathrm{~nm}$. This excitonic feature indicates a monodispersed collection of $\mathrm{Ag}$ nanoparticles in the nanotubes during hybridization. Thus, the introduction of Ag nanoparticles had relatively enhanced the optical properties of $\alpha \mathrm{CNTs}[15,26]$.

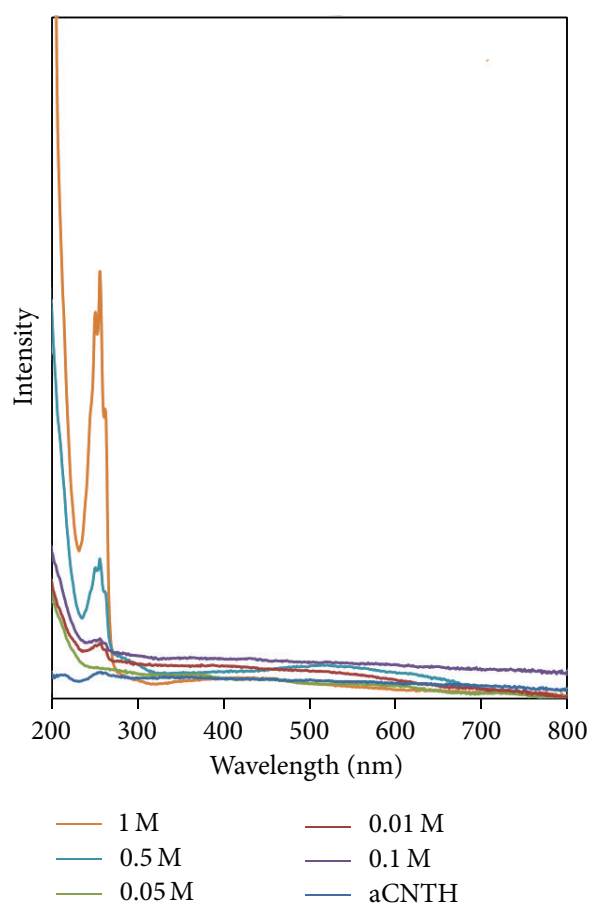

FIgURE 10: Absorption spectra of $\mathrm{HNO}_{3}$ functionalized $\alpha \mathrm{CNTN} / \mathrm{Ag}$ nanohybrids at different molars of $\mathrm{AgNO}_{3}$.

The optical band gap can be evaluated using the Tauc relation $[27,28]$. Consider

$$
(\varepsilon h \nu)=C\left(h \nu-E_{g}\right)^{n},
$$

where $C$ is a constant, $\varepsilon$ is a molar extinction coefficient, $E_{g}$ is the optical band gap of material, and $n$ depends on the type of transition. Figures 11-12 show the $E_{g}$ values obtained from the interception of linear portion in the Tauc plots [28]. Table 1 summarizes the details of $E_{q}$ values. $E_{g}$ decreases significantly after the attachment of $\mathrm{Ag}$ nanoparticles on nanotubes wall. However, the increase molarity of $\mathrm{AgNO}_{3}$ did not further affect the band gap energy. Thus, the attachment of Ag nanoparticles on the nanotubes wall had enhanced the electrical conductivity of the $\alpha$ CNTs.

\section{Conclusions}

$\alpha \mathrm{CNTs} / \mathrm{Ag}$ nanohybrids were successfully synthesized by using a simple chemical technique. FESEM and TEM images showed that Ag nanoparticles were successfully anchored on the nanotubes' walls. They were found to have the tendency to agglomerate at a higher $\mathrm{Ag}$ concentration especially for $\mathrm{HCl}$ functionalized $\alpha \mathrm{CNTH} / \mathrm{Ag}$ nanohybrids. The peaks of newly introduced Ag crystalline structure were detected in $\mathrm{XRD}$ spectra. Besides that, peaks which refer to $\mathrm{AgCl}$ were also found in the nanohybrids system. The attachment of Ag nanoparticles on nanotubes wall enhanced the $G$ band in Raman spectra significantly. As a result, $I_{\mathrm{D}} / I_{\mathrm{G}}$ ratio was gradually decreased, indicating a higher crystallinity degree in nanohybrids samples. The attachment of Ag nanoparticles on $\alpha \mathrm{CNTs}$ was found to enhance their optical properties. 


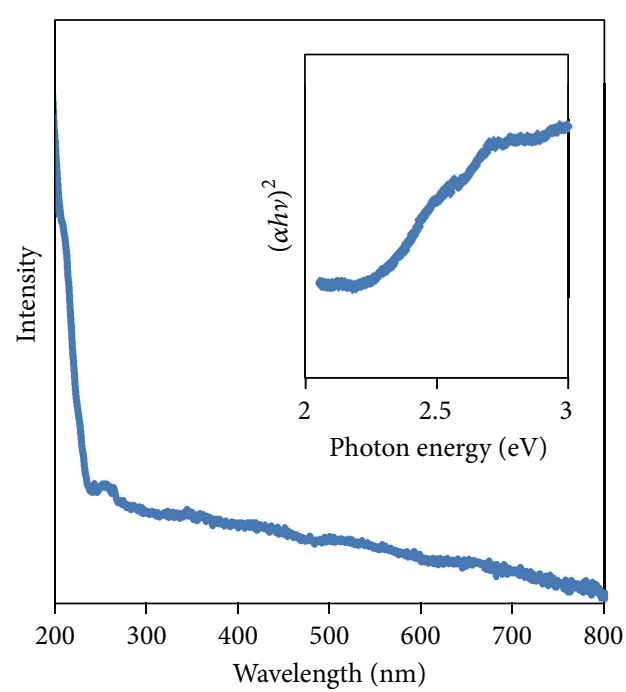

(a)

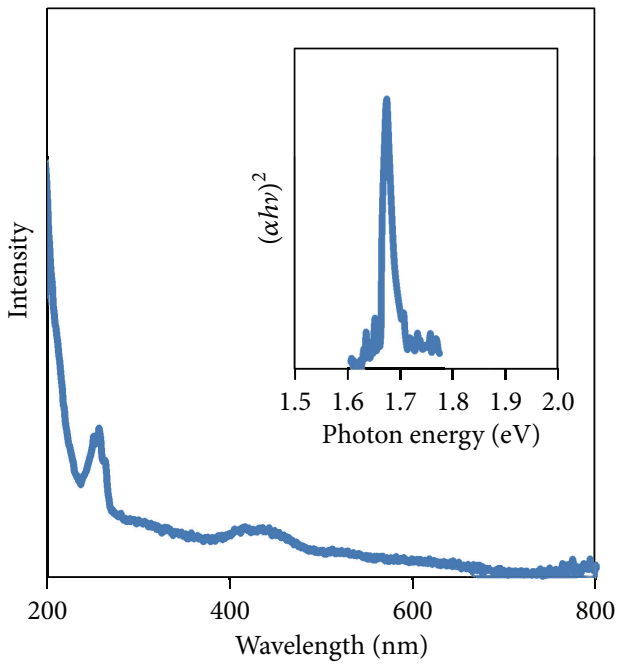

(c)

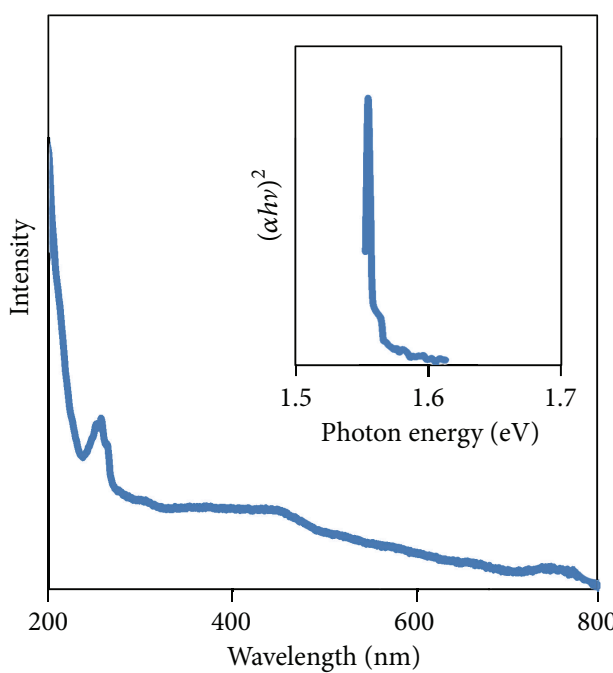

(e)

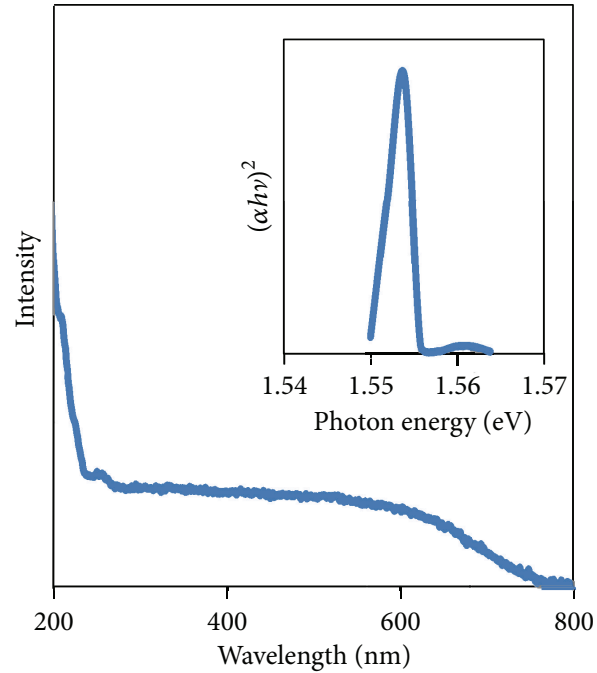

(b)

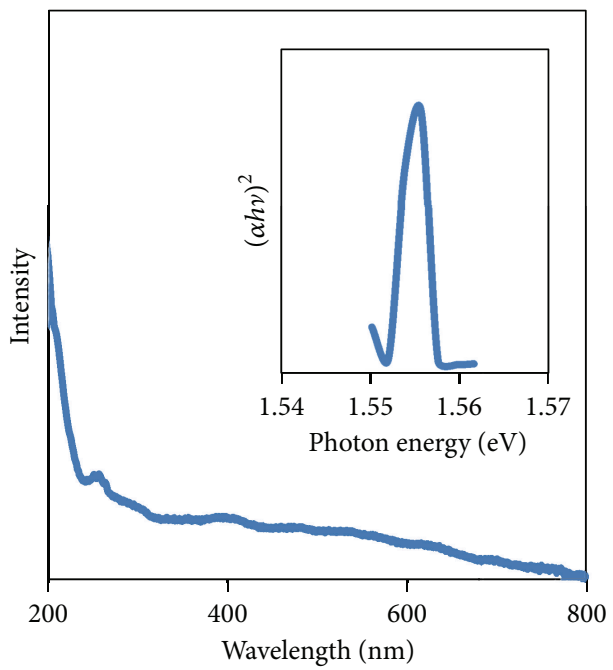

(d)

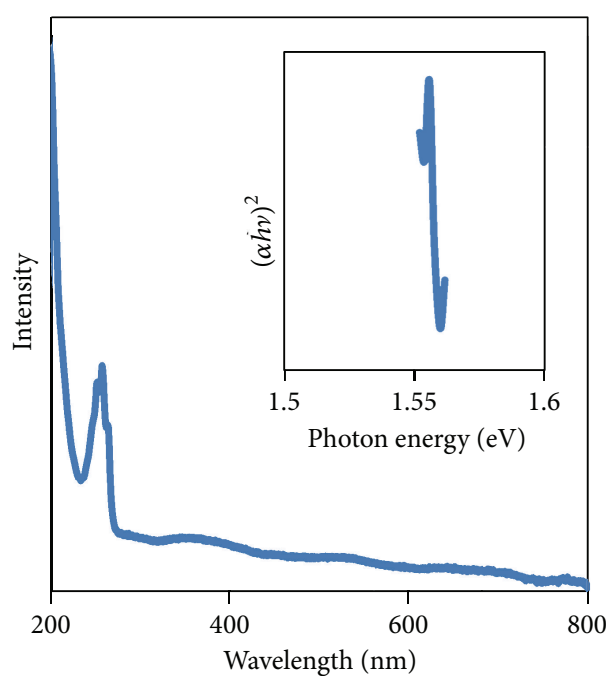

(f)

FIGURE 11: Optical absorbance spectra of $\mathrm{HCl}$ functionalized $\alpha \mathrm{CNTH} / \mathrm{Ag}$ nanohybrids at different molars of $\mathrm{AgNO}_{3}$ : (a) $0 \mathrm{M}$, (b) $0.01 \mathrm{M}$, (c) $0.05 \mathrm{M},(\mathrm{d}) 0.1 \mathrm{M}$, (e) $0.5 \mathrm{M}$, and (f) $1 \mathrm{M}$. Inset shows Tauc plot for each spectrum. 


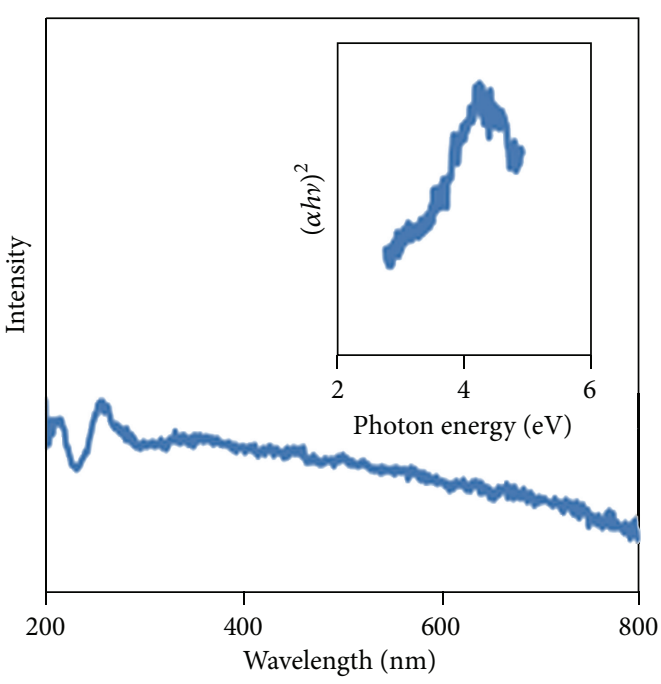

(a)

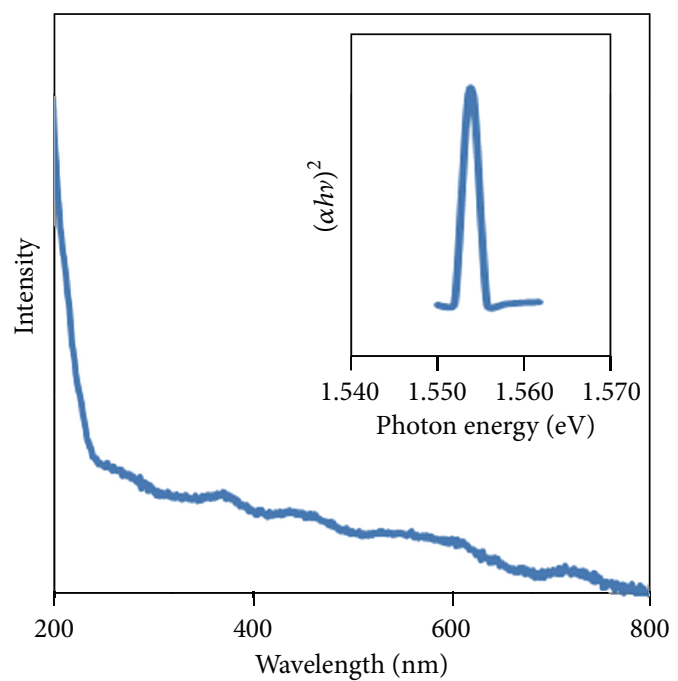

(c)

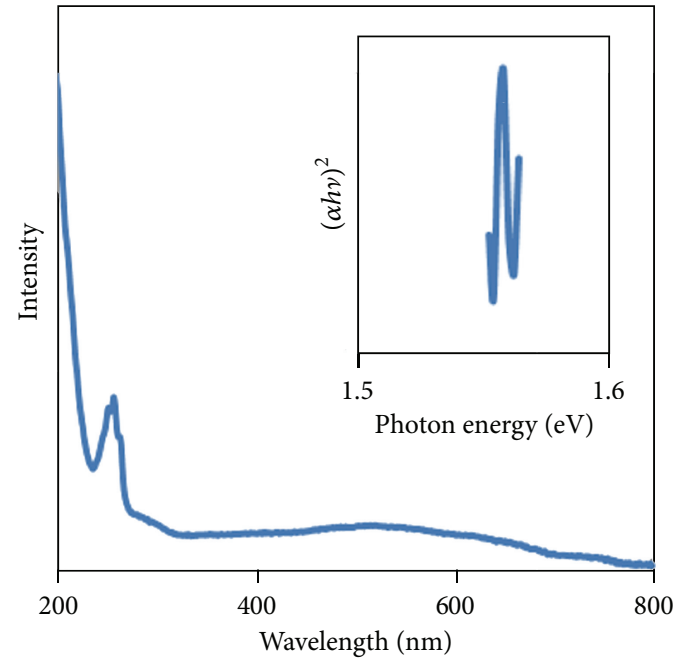

(e)

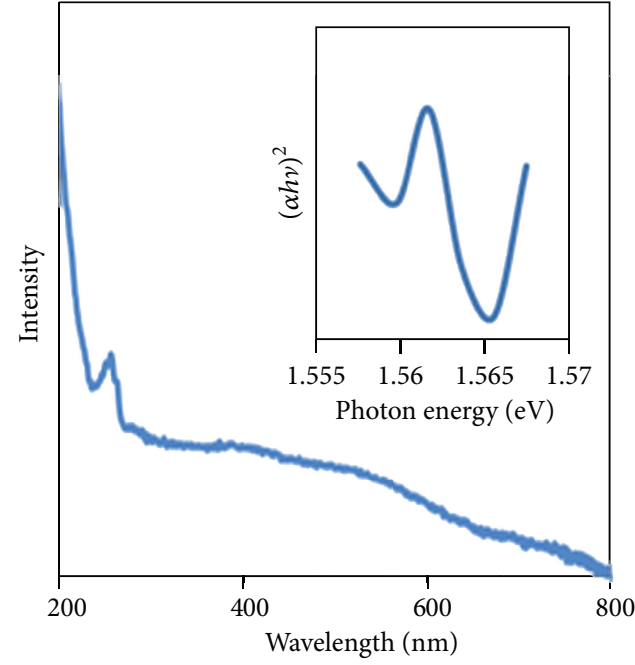

(b)

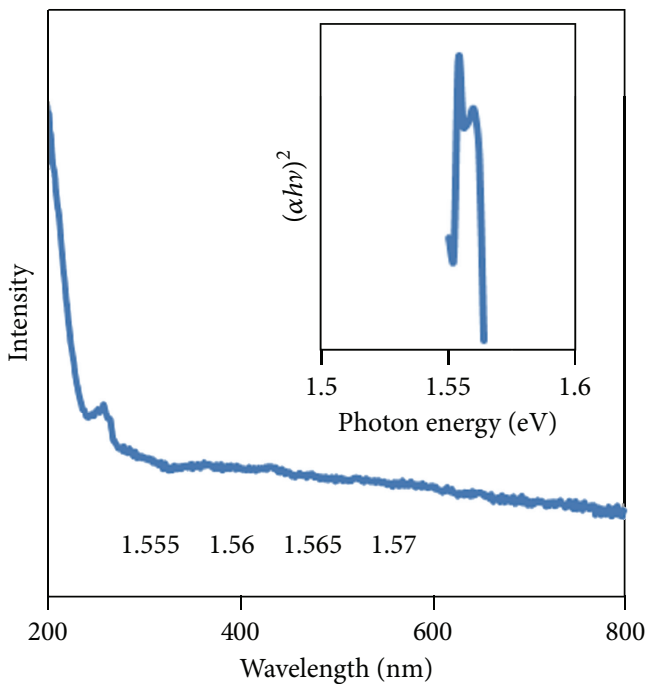

(d)

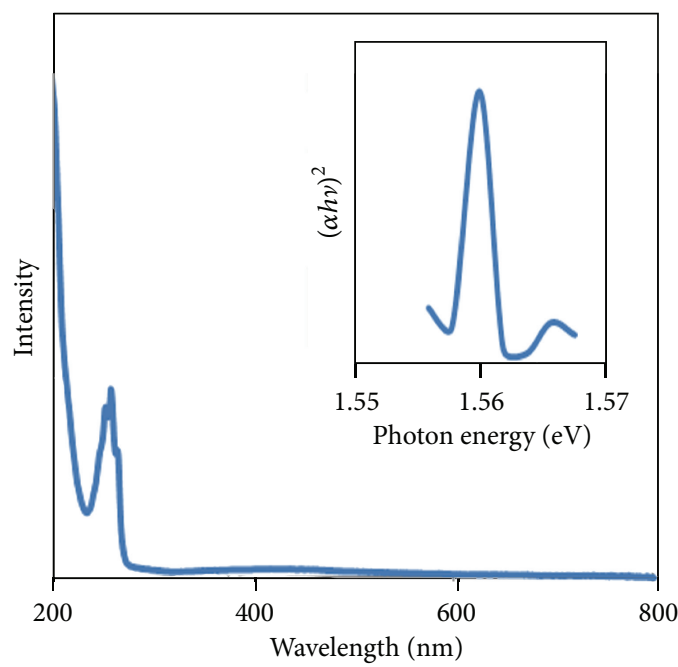

(f)

Figure 12: Optical absorbance spectra of functionalized $\alpha \mathrm{CNTN} / \mathrm{Ag}$ nanohybrids at different molars of $\mathrm{AgNO}_{3}$ : (a) $0 \mathrm{M}$, (b) $0.01 \mathrm{M}$, (c) $0.05 \mathrm{M}$, (d) $0.1 \mathrm{M}$, (e) $0.5 \mathrm{M}$, and (f) $1 \mathrm{M}$. Inset shows Tauc plot for each spectrum. 
TABLE 1: The optical band gap energy $\left(E_{g}\right)$ of all samples $\mathrm{HNO}_{3}$ purified $\alpha$ CNTN/Ag nanohybrids.

\begin{tabular}{lcc}
\hline $\begin{array}{l}\text { Samples at different } \\
\text { molars of } \mathrm{AgNO}_{3}(\mathrm{M})\end{array}$ & $\begin{array}{c}\text { Optical band gap energy }(\mathrm{eV}) \\
\mathrm{HCl} \\
\text { functionalized } \\
\alpha \text {-CNTN/Ag }\end{array}$ & $\begin{array}{c}\mathrm{HNO}_{3} \\
\text { functionalized } \\
\alpha \text {-CNTN/Ag }\end{array}$ \\
\hline 0.00 & 2.09 & 2.30 \\
0.01 & 1.55 & 1.56 \\
0.05 & 1.65 & 1.55 \\
0.10 & 1.55 & 1.55 \\
0.50 & 1.55 & 1.55 \\
1.00 & 1.55 & 1.56 \\
\hline
\end{tabular}

The optical band gap energy of nanohybrids decreased after the loading of $\mathrm{Ag}$ nanoparticles which prove that the $\mathrm{Ag}$ nanoparticles had improved the conductivity properties of $\alpha \mathrm{CNTs}$ themselves. These unique properties from $\alpha \mathrm{CNTs} / \mathrm{Ag}$ nanohybrids system may find their advantages and usefulness for potential applications in various fields, such as medical [29], electronic [30], and waste water treatment [31].

\section{Conflict of Interests}

The authors declare that there is no conflict of interests regarding the publication of this paper.

\section{Acknowledgments}

The authors gratefully acknowledge University of Malaya and Ministry of Higher Education of Malaysia for supporting this work under UM/MOHE HIR Research Grant (UM. C/HIR/MOHE/ENG/12).

\section{References}

[1] S. Iijima, "Helical microtubules of graphitic carbon," Nature, vol. 354, pp. 56-58, 1991.

[2] K. H. Tan and R. J. Mohd, "Surface structure and optical property of amorphous carbon nanotubes hybridized with cadmium selenide quantum dots," Journal of Nanoparticle Research, vol. 15, no. 9, article 1920, 2013.

[3] K. H. Tan, R. Ahmad, B. F. Leo, M. C. Yew, B. C. Ang, and M. R. Johan, "Physico-chemical studies of amorphous carbon nanotubes synthesized at low temperature," Materials Research Bulletin, vol. 47, no. 8, pp. 1849-1854, 2012.

[4] A. H. Lu, W. Schmidt, S. D. Tatar et al., "Formation of amorphous carbon nanotubes on ordered mesoporous silica support," Carbon, vol. 43, no. 8, pp. 1811-1814, 2005.

[5] J. Journet, W. K. Maser, P. Bernier et al., "Large-scale production of single-walled carbon nanotubes by the electric-arc technique," Nature, vol. 388, no. 6644, pp. 756-758, 1997.

[6] M. J. Yacaman, M. M. Yoshida, L. Rendon, and J. G. Santiesteban, "Catalytic growth of carbon microtubules with fullerene structure," Applied Physics Letters, vol. 62, no. 2, pp. 202-204, 1993.
[7] T. Guo, P. Nikolaev, A. G. Rinzler, D. Tomanek, D. T. Colbert, and R. E. Smalley, "Self-assembly of tubular fullerenes," Journal of Physical Chemistry, vol. 99, no. 27, pp. 10694-10697, 1995.

[8] Y. Xiong, Y. Xie, X. Li, and Z. Li, "Production of novel amorphous carbon nanostructures from ferrocene in lowtemperature solution," Carbon, vol. 42, no. 8-9, pp. 1447-1453, 2004.

[9] Y. Liu, J. Tang, X. Chen, W. Chen, G. K. H. Pang, and J. H. Xin, "A wet-chemical route for the decoration of CNTs with silver nanoparticles," Carbon, vol. 44, no. 2, pp. 381-383, 2006.

[10] Z. Zanolli, R. Leghrib, A. Felten, J. Pireaux, E. Llobet, and J. Charlier, "Gas sensing with Au-decorated carbon nanotubes," Journal of American Chemical Society, vol. 6, no. 5, pp. 45924599, 2011.

[11] X. Niu, H. Zhao, C. Chen, and M. Lan, "Platinum nanoparticledecorated carbon nanotube clusters on screen-printed gold nanofilm electrode for enhanced electrocatalytic reduction of hydrogen peroxide," Electrochimica Acta, vol. 65, pp. 97-103, 2012.

[12] Y. Lin, B. Zhou, R. B. Martin et al., "Visible luminescence of carbon nanotubes and dependence on functionalization," Journal of Physical Chemistry B, vol. 109, no. 31, pp. 14779-14782, 2005.

[13] C. H. Xue, R. J. Zhou, M. M. Shi et al., "A green route to water soluble carbon nanotubes and in situ loading of silver nanoparticles," Nanotechnology, vol. 19, no. 32, Article ID 325605, pp. 1-8, 2008.

[14] D. J. Guo and H. L. Li, "Highly dispersed Ag nanoparticles on functional MWNT surfaces for methanol oxidation in alkaline solution," Carbon, vol. 43, no. 6, pp. 1259-1264, 2005.

[15] K. C. Chin, A. Gohel, W. Z. Chen et al., "Gold and silver coated carbon nanotubes: an improved broad-band optical limiter," Chemical Physics Letters, vol. 409, no. 1-3, pp. 85-88, 2005.

[16] Y. Shi, Z. Liu, B. Zhao et al., "Carbon nanotube decorated with silver nanoparticles via noncovalent interaction for a novel nonenzymatic sensor towards hydrogen peroxide reduction," Journal of Electroanalytical Chemistry, vol. 656, no. 1-2, pp. 2933, 2011.

[17] T. Liu, H. Q. Tang, X. M. Cai et al., "A study on bactericidal properties of Ag coated carbon nanotubes," Nuclear Instruments and Methods in Physics Research B, vol. 264, no. 2, pp. 282-286, 2007.

[18] K. Y. Lee, M. Kim, Y. W. Lee, J. Lee, and S. W. Han, "Fabrication of metal nanoparticles-carbon nanotubes composite materials in solution," Chemical Physics Letters, vol. 440, no. 4-6, pp. 249252, 2007.

[19] G. Chen, J. Qiu, and H. Qiu, "Filling double-walled carbon nanotubes with $\mathrm{AgCl}$ nanowires," Scripta Materialia, vol. 58, no. 6, pp. 457-460, 2008.

[20] W. M. Anthony, R. W. Eric, and L. F. Ray, "A comparative study of single-walled carbon nanotube purification techniques using Raman spectroscopy," Spectrochimica Acta A: Molecular and Biomolecular Spectroscopy, vol. 71, no. 1, pp. 140-142, 2008.

[21] H. Yang, P. Mercier, S. C. Wang, and D. L. Akins, "High-pressure synthesis of carbon nanotubes with a variety of morphologies," Chemical Physics Letters, vol. 416, no. 1-3, pp. 18-21, 2005.

[22] S. Su, W. Chiang, C. Lin, and Y. Meiso, "Multi-wall carbon nanotubes: purification, morphology and field emission performance," Physica E: Low-Dimensional Systems and Nanostructures, vol. 40, no. 7, pp. 2322-2326, 2008. 
[23] A. N. Sidorov, G. W. Slawinski, A. H. Jayatissa, F. P. Zamborini, and G. U. Sumanasekera, "A surface-enhanced Raman spectroscopy study of thin graphene sheets functionalized with gold and silver nanostructures by seed-mediated growth," Carbon, vol. 50, no. 2, pp. 699-705, 2012.

[24] Y. Liu, L. Yu, S. Zhang, J. Yuan, L. Shi, and L. Zheng, "Dispersion of multiwalled carbon nanotubes by ionic liquid-type Gemini imidazolium surfactants in aqueous solution," Colloids and Surfaces A, vol. 359, no. 1-3, pp. 66-70, 2010.

[25] S. Asta, P. Igoris, P. Judita, J. Algimantas, and G. Asta, "Analysis of silver nanoparticles produced by chemical reduction of silver salt solution," Materials Science-Medziagotyra, vol. 12, no. 4, pp. 287-291, 2006.

[26] M. A. Noginov, G. Zhu, M. Bahoura et al., "The effect of gain and absorption on surface plasmons in metal nanoparticles," Applied Physics B, vol. 86, no. 3, pp. 455-460, 2007.

[27] G. Lazar, "Some peculiarities in ultraviolet absorption spectra for hydrogenated amorphous carbon thin films," Materials Letters, vol. 57, no. 3, pp. 586-588, 2002.

[28] S. K. Mehta, S. Kumar, S. Chaudhary, and K. K. Bhasin, "Nucleation and growth of surfactant-passivated CdS and HgS nanoparticles: time-dependent absorption and luminescence profiles," Nanoscale, vol. 2, no. 1, pp. 145-152, 2010.

[29] V. K. Rangari, G. M. Mohammad, S. Jeelani et al., "Synthesis of Ag/CNT hybrid nanoparticles and fabrication of their nylon-6 polymer nanocomposite fibers for antimicrobial applications," Nanotechnology, vol. 21, no. 9, Article ID 095102, 2010.

[30] Y. Peng and Q. Chen, "Fabrication of one-dimensional Ag/multiwalled carbon nanotube nano-composite," Nanoscale Research Letters, vol. 7, article 195, 2012.

[31] L. P. Lukhele, R. W. M. Krause, B. B. Mamba, and M. N. B. Momba, "Synthesis of silver impregnated carbon nanotubes and cyclodextrin polyurethanes for the disinfection of water," Water SA, vol. 36, no. 4, pp. 433-436, 2010. 

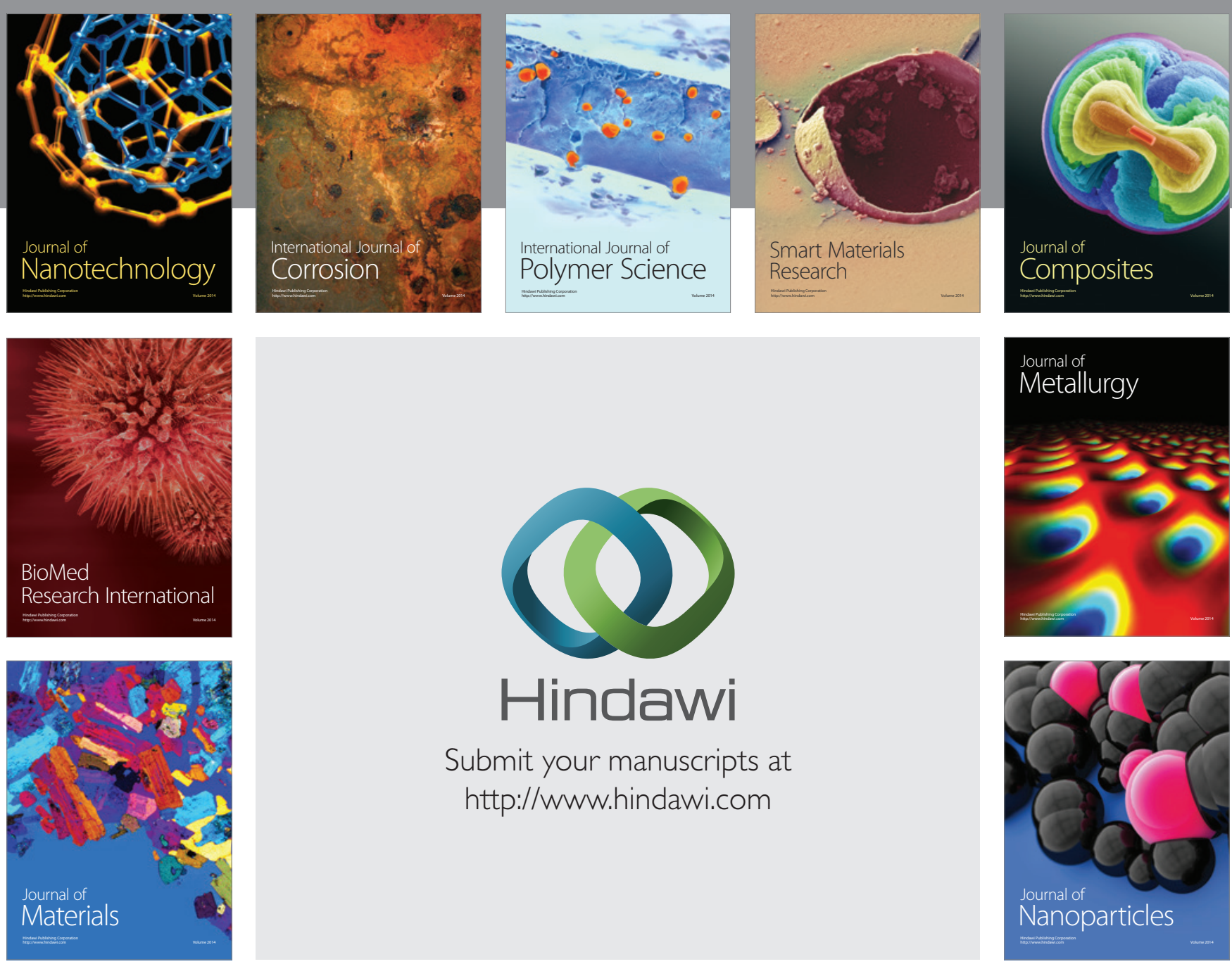

Submit your manuscripts at http://www.hindawi.com
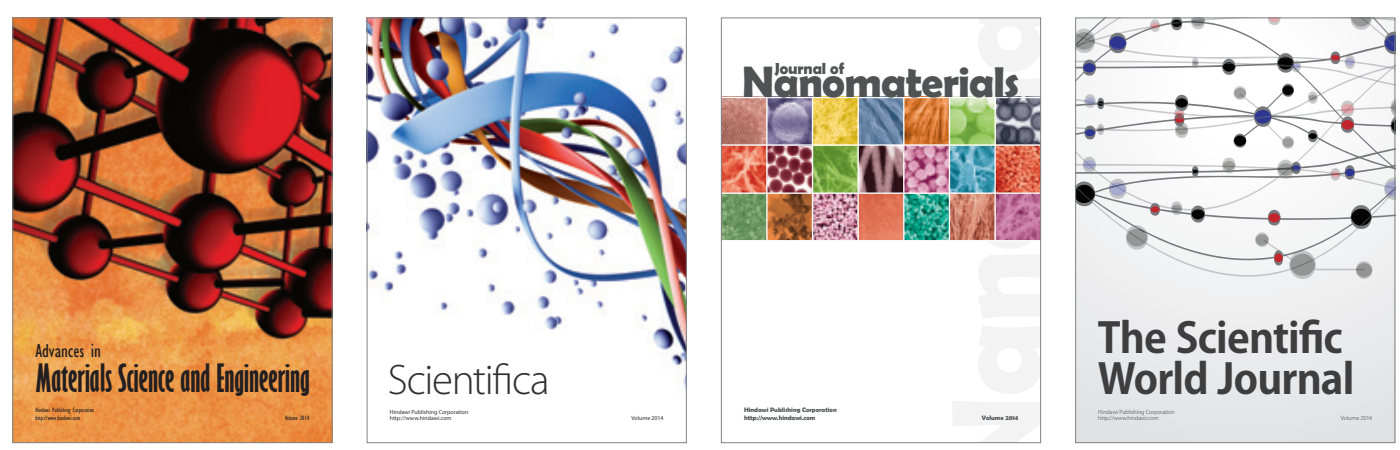

\section{The Scientific World Journal}
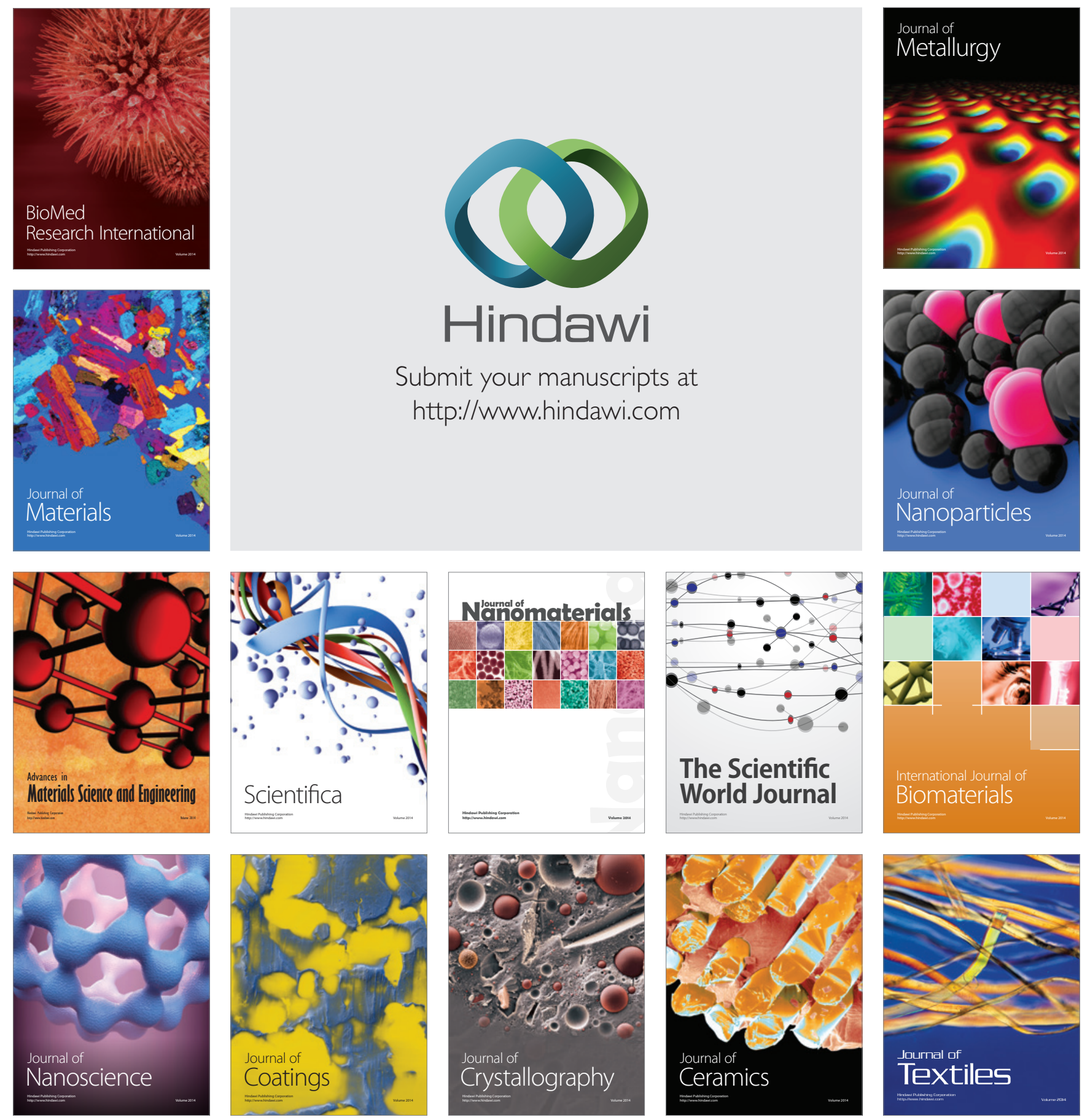